\title{
STRUCTURAL AND FUNCTIONAL ANALYSES OF THE OCCIPITAL CORTEX IN VISUAL IMPAIRED PATIENTS WITH VISUAL LOSS BEFORE 14 YEARS OLD
}

\author{
Elcio Juliato Piovesan ${ }^{1}$, Marcos Cristiano Lange ${ }^{1}$, Pedro André Kowacs ${ }^{1}$, Hudson Famelli ${ }^{1}$, \\ Lineu Cesar Werneck ${ }^{1}$, Airton Yamada², Guilberto M inguetti ${ }^{3}$
}

\begin{abstract}
Single photon emission tomography (SPECT) perfusion images of the brain of individuals with complete visual loss before the age of 14 were carried out and compared to those of visually normal subjects, in order to assess hypothetical differences in brain structural and metabolism between the two groups. Study group was comprised by 2 females and 3 males, aged $30 \pm 10$ years. Controls were composed by 6 females and 5 males aged $41.5 \pm 3.8$ years. All individuals were submitted to physical and neurological examinations, and to MRI and to SPECT. Blind subjects presented larger perfusion measurements bilaterally in their medial temporal lobes ( $p=0.030$, right side; $p=0.01$, left side), but smaller perfusion measurements in their left frontotemporal area than controls $(p=0.026)$. Intragroup analysis of the study group disclosed asymmetric perfusion, lesser in the left temporal and parietal areas ( $p=0.026$ and $p<0.0001$, respectively) compared to the right side. In the healthy controls, reduced perfusion was also noted at the left parietal areas when compared to the right side $(p=0.035)$. The study revealed that completely blind patients that became visually impaired before the age of 14 in spite of not having MRI detectable changes in their brain's anatomy do present increases in perfusion of their left and right medial temporal lobes, and a reduction in the perfusion of the left frontotemporal area, as compared to normal controls. While the increases in blood flow may reflect compensatory mechanisms for visual deprivation, the significance of the diminished perfusion in the left frontotemporal area remains elusive.
\end{abstract}

KEY WORDS: blindness, cortical perfusion, neuroplasticity, visual deprivation, visual loss.

\begin{abstract}
Análise estrutural e funcional do córtex visual em pacientes cegos com perda visual antes dos 14 anos de idade RESUMO - $O$ estudo analiso o comportamento do córtex occipital em indivíduos com perda visual total antes dos 14 anos de idade. Foram estudados cinco pacientes, 2 femininos e 3 masculinos, com idade média de 30 anos $( \pm 10)$ constituindo grupo cegos. Para o grupo controle foram estudados 11 voluntários com visão normal, 5 masculinos e 6 femininos com idade média de 41,53 anos $( \pm 3,81)$. Todos os pacientes foram submetidos a exame físico, neurológico e a exames de ressonância magnética encefálica (RME) e tomografia por emissão de fóton único (SPECT). Os voluntários apresentaram RME e SPECT normais. A imagem de RME não demonstrou alterações no córtex occipital dos cegos. Entretanto, estes apresentavam fluxo sanguíneo maior nas regiões temporal medial direita (TMD) $(p=0,030)$ e temporal medial esquerda (TME) $(p=0,010)$ e menor fluxo sanguíneo na região fronto-temporal esquerda ( $\mathrm{FTE})(\mathrm{p}=0,026)$. Comparando-se os lados direito e esquerdo, os cegos apresentavam redução de fluxo sanguíneo na região temporal esquerda $(p=0,026)$ e parietal esquerda $(p<0,0001)$. Os voluntários apresentavam fluxo sanguíneo reduzido na região parietal esquerda $(p=0,035)$. 0 estudo mostra que pacientes deficientes visuais totais, com perda visual adquirida antes dos 14 anos, não apresentam alterações estruturais na RME quando comparados com o grupo de voluntários. Observa-se um aumento do fluxo sanguíneo nas regiões TMD e TME e redução na região FTE.

PALAVRAS-CHAVE: cegos, metabolismo cortical, neuroplasticidade, perda visual, privação visual.
\end{abstract}

The outer layer of the cerebral cortex is divided into several areas specialised in detecting and processing sensory signals from the eyes and ears and from receptors for touch and nociceptors. Everyday experience illustrates that, in spite of dealing with different modalities of information, the sensorial regions of the cortex must cooperate with each other to integrate stimuli received from outside world ${ }^{1}$.

In complete blindness, because of a lack of visual input, we have a rare opportunity of studying the effects of the lack of connection of the occipital cortex, as well as the functional behavior of the occi-

\footnotetext{
'Unidade de Cefaléia, Especialidade de Neurologia do Departamento de Clínica Médica do Hospital de Clínicas da Universidade Federal do Paraná (UFPR), Curitiba PR, Brazil; ${ }^{2}$ Centro de Radio Imunoensaio (CERMEN); ${ }^{3}$ Centro de Tomografia Axial Computadorizada (CETAC). This project was financed partially by the PIBIC/CNPq, CETAC and CERMEN.
}

Received 31 January 2002, received in final from 22 May 2002. Accepted 4 June 2002.

Dr. Elcio Juliato Piovesan - Serviço de Neurologia, Hospital de Clínicas da UFPR - Rua General Carneiro 181/ $12^{\circ}$ andar - 80060-900 Curitiba PR- Brasil. E-mail: piovesan@ avalon.sul.com.br 
pital areas facing this unnatural condition. Bearing this aspects in mind, we have planned to study the structural and function of the brain of individuals with complete visual loss before the age of 14, by using magnetic resonance imaging (MRI) and single photon emission tomography (SPECT) .

\section{METHOD}

Selection criteria consisted of: presence of Visual Deficiency Class 52; installation of the visual loss before the age of 14; a retrobulbar location of the aetiology; lack of active systemic or neurological disease; older than 18; ability for reading in Braille and completion of the informed consent.

Patients.The Study Group (BLINDS) was composed initially of seven individuals, with visual loss before the age of 14, living in the city of Curitiba, South Brazil. Patients were recruited through phone calls, and two of them refused to continue in the protocol. Of the five remaining patients, three were male, and two female. Mean age was 30 \pm 10 years. Two of them were blind since birth, one became blind at the age of two, and another at the age of five. Measles caused blindness in one of the patients, glaucoma in other, cataract in a other and a retinoblastoma in another. In the fifth patient aetiology of the blindness was unknown.

Controls. For the Control Group (CONTROLS) 11 healthy volunteers were studied. Five of them were male and six female. Mean age was $41.53 \pm 3.81$ years.

Imaging and image processing techniques. A 1.5 Tesla Philips Gyroscan ACS - NT was used to obtain the MRI images, weighted in T1, T2 and FLAIR protocols for sagittal, coronal and axial slices. SPECT images were obtained with a Cardial-Elscint equipment, with two fixed rotating detectors in $90^{\circ}$, and high spacial resolution collimators. As 740 $\mathrm{MBq}(20 \mathrm{mCi})$ of etylcysteinate dimer (ECD) marked with Tecnecium-99mm were used as radiotracer. All MRI and SPECT exams were interpreted by the same professionals, respectively. SPECT images were analyzed at sixlevels, starting caudally towards the top of the head: Level 1: fronto-

Table. Demographic characteristics of the study group.

\begin{tabular}{ccccc}
\hline Patient & Sex & Age & $\begin{array}{c}\text { Cause of the } \\
\text { visual loss }\end{array}$ & $\begin{array}{c}\text { Age of } \\
\text { visual loss }\end{array}$ \\
\hline 1 & M & 20 & Ignored & rising \\
2 & M & 41 & Measles & 2 years \\
3 & M & 40 & Glaucoma & rising \\
4 & F & 30 & Retinoblastoma & 5 years \\
5 & F & 21 & Cataract & 10 years \\
\hline
\end{tabular}

$M$, male; $F$, female. basal area, pons and cerebellum; Level 2: lateral and medial temporal lobes; Level 3: six pixels in the cortical areas, from the frontal cortex to the occipital lobes, with four pixels surrounding the basal ganglia; Levels 4 to 6 : cortical pixels as level 3, without subcortical pixels. Values obtained at the cerebellar placed pixels were used as reference for the analysis of subsequent findings.

Ethics. The study was approved by the Ethics Committee on Human Research of Hospital de Clínicas - UFPR. All the included individuals were asked to read and sign an informed consent before being included. A Braille written consent form was given to the blind volunteers.

Data analysis and statistics. The Student t-test was used for the analysis of the independent samples, through the "Primer of Biostatistics" software. The level of significance required was $5 \%$ (0.05).

\section{RESULTS}

Control group MRI Imaging and SPECT results. All the CONTROLS presented normal MR images of the brain and normal SPECT perfusion images of the brain.

Study group MRI imaging. None of the five individuals of the BLNDS group presented atrophy of the occipital cortex or of other regions. Brain images were normal in 4; however, in Patient 2 diffuse white matter abnormalities suggestive of microangiopathy were observed. Regarding the optical pathways, three patients lacked the eyeballs, one patient presented signal abnormalities in both eyeballs and one patient presented absence of the crystalline. Bilateral atrophy of the optic nerve was seen in one patient, and unilateral atrophy of the left optic nerve in other (Fig 1).

SPECT comparative analysis between groups (BLNDS versus CONTROLS). At Level 2, BLNDS presented higher perfusion values at the right $(70.4 \pm 4.2$ right versus $61.1 \pm 5.1$ left) and left medial temporal regions ( $70 \pm 4.6$ right versus $60.4 \pm 3.8$ left), as compared to CONTROLS $(p=0.03$ and $p=0.026$, respectively). At Level 3, BLNDS presented lower perfusion values at the left frontotemporal pixel $(59.8 \pm 4.1$ versus $69 \pm 4.8, p=0.026$ ). Borderline diminished perfusion was also observed at the left temporal and left temporoparietal areas $(p=0.066$ and $p=0.055$, respectively) in the BLNDS (Figs 2 and 3).

\section{SPECT intragroup analysis}

Study group. Significant asymmetries were found in the brain of the BUNDS individuals: at Level 3, lower values were observed at the left temporal re- 


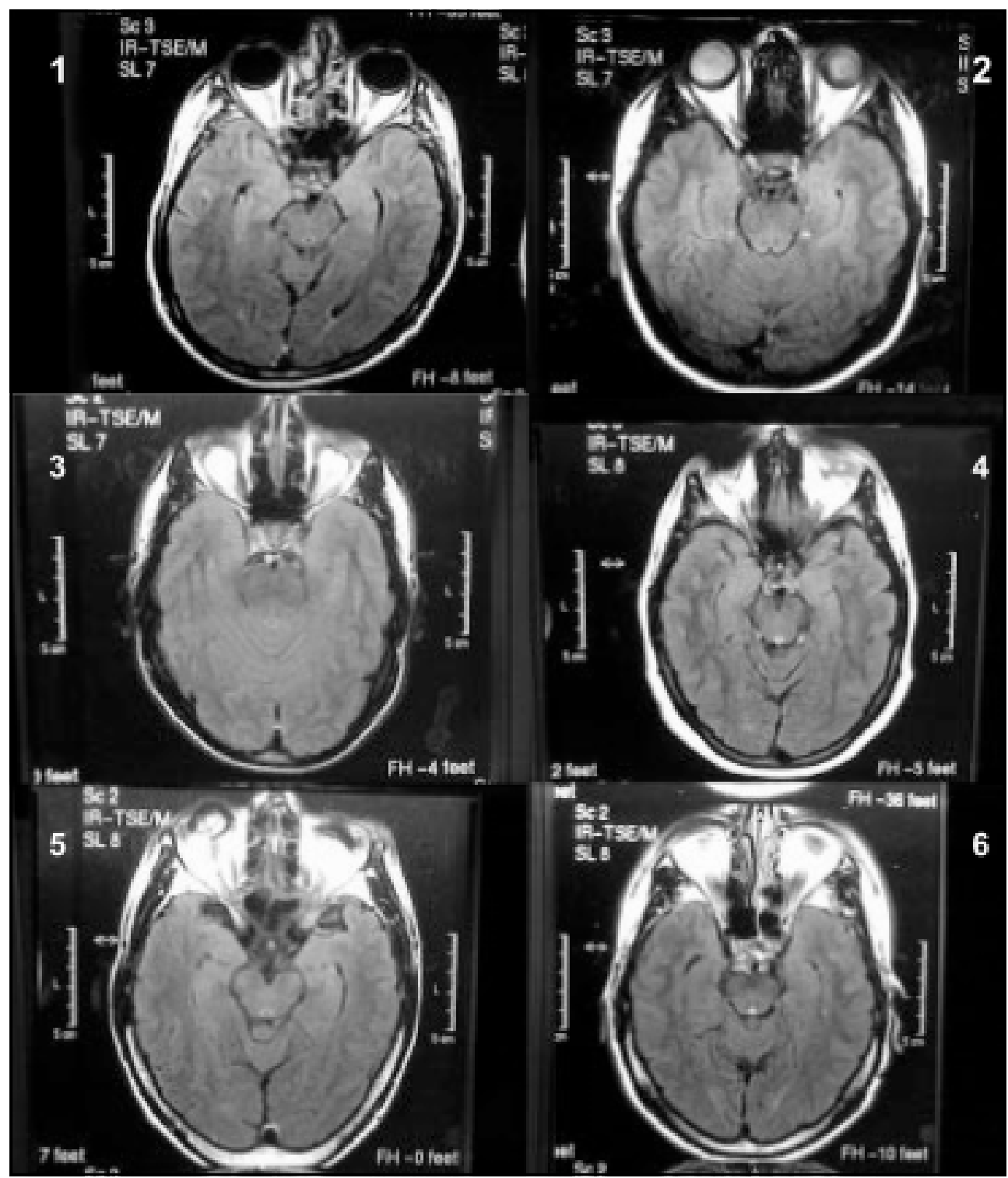

Fig 1. MRI of the patients(T2-FLAIR): Normal visual pathways (Patient 1); absence of the crystalline (Patient 2); lacked the eyeballs (Patients 3,4,and 6); signal abnormalities in both eyeballs (Patient 5).

gion $(67.2 \pm 4.1$ right versus $60.4 \pm 3.8$ left, $p=0.026)$ and at the left temporoparietal region $(70.6 \pm 2.1$ right versus $64.2 \pm 1.6$ left, $p<0.0001$ ) as compared to their right counterparts. Borderline results were observed in Level 3 at the left frontotemporal $(p=0.080)$ and in Level 5 at the left frontal pixel $(p=0.095)$.

Controls. Significant perfusion asymmetries were observed in the brains of the CONTROLS in the Level 4 , lower at the left temporal pixel $(68.3 \pm 4.1$ right versus $65.2 \pm 2$ left, $p=0.035$ ).

\section{DISCUSSION}

The loss of visual inputsfrom eye disease or retrobulbar disorders results in a disconnection of the occi- pital cortex from external stimuli in completely blind individuals. However, previous MRI studies have failed to reveal structural developmental abnormalities in those patients such as occipital lobe atrophy-10. There is however, experimental evidence showing that precocious visual privation in non human primates results in microscopic changes in this area ${ }^{4}$.

Positron emission tomography (PET) studies, functional MRI (f-MRI) and transcranial magnetic stimulation (TMS) studies in blind individuals with early visual loss have demonstrated a recruitment of the occipital cortex for other neuronal stimuli, such as tactile and auditory ${ }^{8,11-13}$. These cross-modal activation reflects cortical plasticity and depends on the frequency and time of use of the area analyzed. It has been proposed that the plasticity of the occipital 


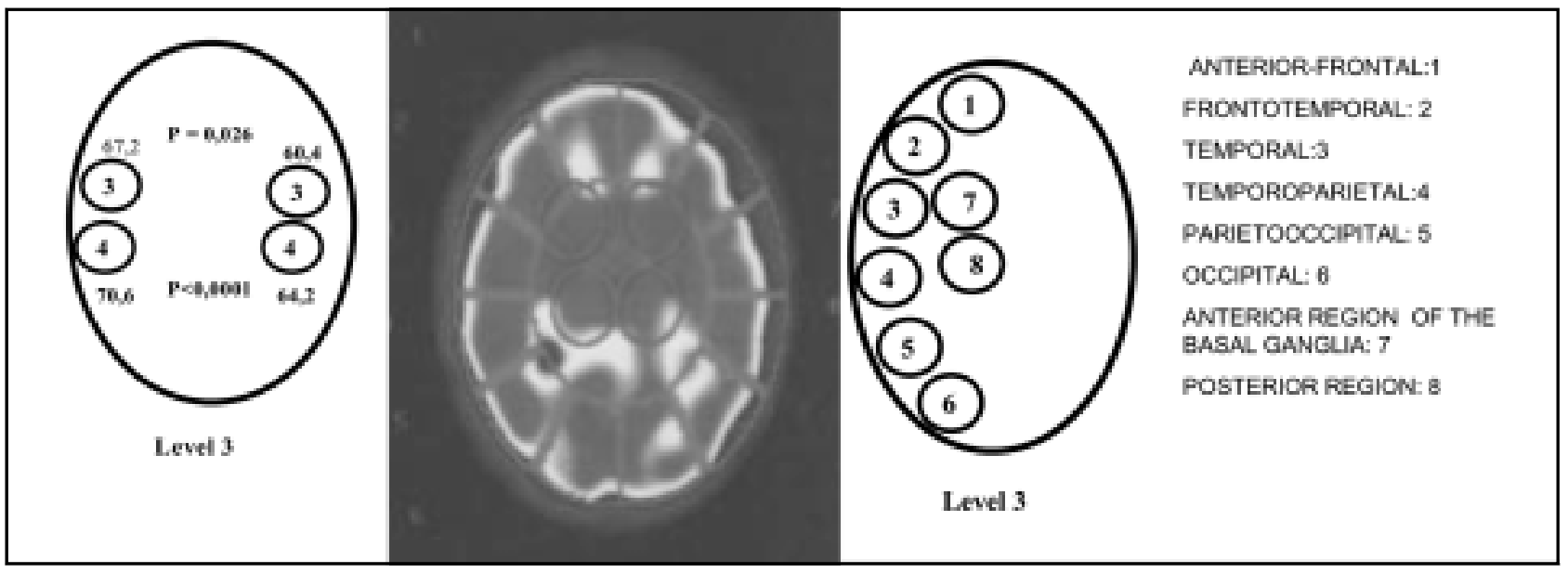

Fig 2. Outline demonstrating the comparison among the sides right and left for the study group.

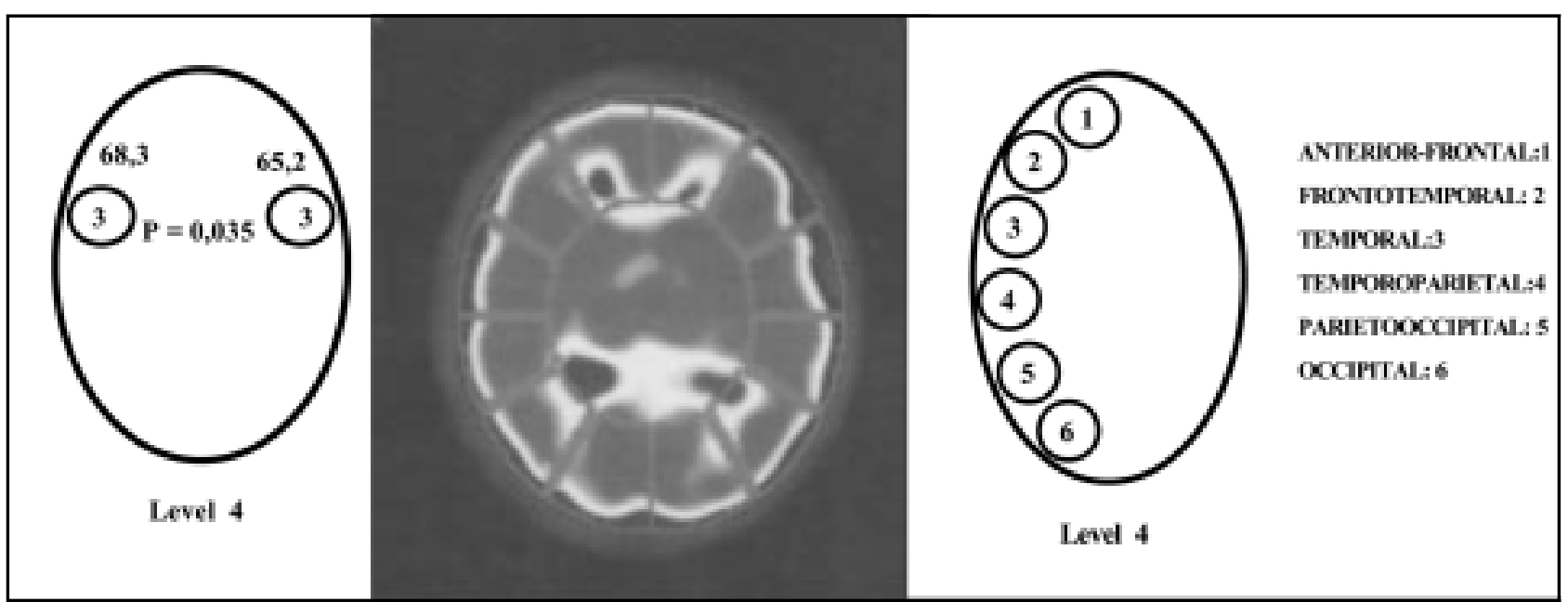

Fig 3. Outline demonstrating the comparison among the sides right and left for the control group.

cortex in blind individuals can be relevant for the increased abilities in tactile perception disclosed by them $9,11,14-16$.

Studies comparing the metabolism of glucose, the consumption of oxygen, the cerebral blood flow and the electric activity of the primary visual cortex of blind subjects with that of healthy controls have failed to show significant differences ${ }^{6,7,10}$. Cohen and collaborators, by comparing subjects with congenital or early visual loss with individuals with late visual loss, have demonstrated that occipital cortex plasticity occurs only in individuals that became blind before the age of $14^{5}$.

Visual experience is an important factor for the early organization of the visual cortex. Cortical plasticity of the occipital cortex will be directly related to the timing of visual loss ${ }^{17,18}$, being interrupted at the age of $14^{5}$. This upper bracket limit coincides with puberty and is associated with a reduction of supernumerary synapses inside the visual cortex ${ }^{19,20}$.
Our finding of lack of anatomical differences between the BLNDS and the CONTROLS is similar to previous studies that have analyzed the structure of the cerebral cortex of visually impaired subjects ${ }^{3-5}$. The abnormalities found in the optic pathways in $40 \%$ of our cases echoed the findings of Breitenseher and col., that have observed hypoplasia or atrophies in the optical nerve, tract or optic radiations in 58\% of their patients, without other abnormalities in another patient ${ }^{3}$. However, it is reasonable to assume that the abnormalities found in the optical pathways of the BLNDS were secondary to the cause of the blindness rather than being a consequence of the lack of visual stimuli.

The lack of differences in occipital cortexperfusion values between BLNDS and CONTROLS observed in our study suggested similar metabolic activity rates in the occipital cortical structures of both groups. This finding is similar to that obtained by Ishikawa and col., that compared through SPECT the perfusion of the primary visual cortex of four visually impaired 
subjects with that of normal controls? ${ }^{7}$. However, in our study, differences were observed, such as an bilateral increase in the blood flow in the medial temporal voxels and a reduced perfusion in the left frontotemporal areas. If our findings are not contaminated by a beta type error, then they may reflect functional changes induced by the loss of visual input. Along the same line of though, it is reasonable to conceive that the normal blood flow found in the occipital cortex of the BLNDS reflects the effects of neuroplasticity-induced functional changes.

Neuroplasticity is a process that happens thanks to the integration of several sensorial channels, such as visual, tactile and nociceptive, processed through multimodal neurons and at cortical "cross modal" association areas ${ }^{21}$. Cortical plasticity does not occur only in the occipital cortex but also in other cortical areas such as motor, sensory and tactile, being dependent of the frequency and using time of the analyzed area9,15. Being so, the increased blood flow in the temporal voxels of the BLNDS could perhaps reflect increase hearing awareness. Cross modal plasticity has been hypothesized to help the tactile perception abilities of visual impaired subjects ${ }^{11,16,22}$. Plasticity involves changes and an increase in the cortical representation of the analyzed area, due to an enhanced peripheral input secondary to an adaptative phenomenon of cortical representation ${ }^{15,23}$.

This crossmodal effect arises even when the tactile cues tasked are irrelevant and do not predict the location of the visual targets, suggesting an exogenous (stimulus driven) attentional mechanism ${ }^{20}$. Recent studies that analyzed the effective connectivity have suggested that tactile input to the somatosensory cortex may influence the visual cortex via back projection through association areas in the parietal lobe ${ }^{24}$. The existing relationships between the primary and secondary visual cortical areas and the tactile sensory cortex is explained by the bimodal neurons and by the crossmodal connections. The loss of the visual inputs to the occipital cortex also influences the trigeminal nociceptive discrimination ${ }^{25}$. To conclude, the visual cortex neurons are not tightly bound to visual function, but also able to process other tasks such as Braille reading, and tactile and trigeminal nociceptive discrimination ${ }^{13,25,26}$.

Finally, our data has reinforced the previous findings of the lack of structural changes in the visual cortex in patients with early visual loss due to disease of the optical pathways. However, the finding of significant changes in cerebral cortical perfusion sug- gest the existence of active neuroplasticity mechanisms operating on the patient's adaptation.

\section{REFERENCES}

1. Gelder B. Moreto seeing than meets theeye. Science2000;289:1148-1149.

2. OMS. Classificação estatística internacional de doenças e problemas relacionados a saúde CID10 . 4.Ed, São Paulo: EDUSP, 1997;1:442-443.

3. Breitenseher M, Uhl F, Prayer Wimberger D, Deecke L, Trattnig S, Kramer J. Morphological dissociation between visual pathways and cortex: MRI of visually-deprived patients with congenital peripheral blindness. Neuroradiology 1998;40:424-427.

4. Buchel C, Price C, Frackowiak RSJ, Friston K. Different activation patterns in the visual cortex of late and congenitally blind subjects. Brain 1998;121:409-419.

5. Cohen LG, Weeks RA, Sadato N, Celnik P, Ishii K, Hallet M. Period of susceptibility for cross-modal plasticity in the blind. Ann Neurol 1999;45:451-460.

6. De Volder AG, Bol A, Blin J, et al. Brain energy metabolism in early blind subjects: neural activity in the visual cortex. Brain Res 1997;750:235-244.

7. Ishikawa N, Nishijo K, Satou M, TakedaT, Itai Y. Study on the primary cortex of visually impaired subjects by means of 123 I-IMP SPECT and MRI. Ann Nudl Med 1995;9:105-108.

8. KujalaT, Huotilainen M, Sinkkonen J. et al. Visual cortex activation in blind humans during sound discrimination. Neurosci Lett 1995;183:143-146.

9. Pascual-Leone A, Wassermann EM, Sadato N, Hallet M. The role of reading activity on the modulation of motor cortical outputs to the reading hand in Braille readers. Ann Neurol 1995;38:910-915.

10. Wanet-Defalque MC, Veraart C, De Volder A, et al. High metabolic activity in the visual cortex of early blind human subjects. Brain Res 1988;446:369-373.

11. Cohen LG, Celnik P, Pascual-Leone A, et al. Functional relevance of cross-modal plasticity in blind humans. N ature 1997;389:180-183.

12. Sadato $N$, Hallet $M$. fMRI occipital activation by tactile stimulation in a blind man. Neurology 1999;52:423.

13. Sadato N, Pasaual-LeoneA, Grafman J, Deiber MP, Ibañez V, HalletM. Neural networks for Braille reading by the blind. Brain 1998;121:1213-1229.

14. Pascual-Leone A, Cammarota A, Wassermann EM, Brasil-N eto JP, Cohen LG, Hallet M. Modulation of motor cortical outputs to the reading hand of Braille readers. Ann Neurol 1993;34:33-37.

15. Sterr A, Muller MM, Elbert T, Rockstroh B, Pantev C, Taub E. Perceptual correlates of changes in cortical representation of fingers in blind multifinger Braille readers. J Neurosci 1998;18:4417-4423.

16. Sunanto J, $\mathrm{N}$ akata $\mathrm{H}$. Indirect tactual discrimination of heights by blind and blindfolded sighted subjects. Percept Mot Skills 1998;86:383-386.

17. Hubel DH, Wiesel TN. Ferrier Lecture. Functional architecture of macaque monkey visual cortex. Proc R Soc Lond Biol Sci 1977;198:1-59.

18. Price DJ, Ferrer JM, Blakemore C, Kato N. Postnatal development and plasticity of corticocortical projections from area 17 to area 18 in the cat's visual cortex. J Neurosci 1994;14:2747-2762.

19. BourgeoisJP, RakicP. Changes of synaptic density in the primary visual cortex of the macaque monkey from fetal to adult stage. J Neurosci 1993;13:2801-2820.

20. Veraart C, De Volder AG, Wanet-Defalque MC, Bol A, Michel C, Goffinet AM. Glucose utilization in human visual cortex is abnormally elevated in blindness of early onset but decreased in blindness of late onset. Brain Res 1990;510:115-121.

21. Piovesan EJ, Lange MC, Kowacs PA, Pacheco C, Werneck LC. Evaluation of headache intensity in migrainous patients with visual handicap through thetactileanalogical scale(TAS). A rq N europsiquiatr 2001;59:702-707.

22. Deibert E, Kraut M, Kremen S, Hart J Jr. Neural pathways in tactile object recognition. Neurology 1999;52:1413-1417.

23. Werring DJ, Bullmore ET, Toosy A, et al. Recovery from optic neuritis is associated with a change in the distribution of cerebral response to visual stimulation: a functional magnetic resonance imaging study. J Neurol Neurosurg Psychiatry 2000;68:441-449.

24. Macaluso E, Frith $C D$, Driver J. Modulation of human visual cortex by crossmodal spatial attention. Science 2000;289:1206-1208.

25. Piovesan EJ, Lange MC, Pacheco CG, Fameli H, Kowacs PA, Werneck LC. Influence of visual loss on the threshold of pain perception. Neurology 2001;56(Suppl 3):A 65.

26. Sathian K, Zangaladze A, Hoffman JM, Grafton ST. Feeling with the mind's eye. Neuroreport 1997;8:3877-3881. 